\title{
EVALUATION OF AN ICT SKILLS PROGRAM: ENHANCING GRADUATE CAPABILITIES AND EMPLOYABILITY
}

\author{
Theo Papadopoulos \\ Victoria University \\ PO Box 14428 Melbourne 8001 Australia \\ theo.papadopoulos@vu.edu.au \\ Christine Armatas \\ Victoria University \\ 77-91 St Georges Road Preston 3072 Australia \\ christine.armatas@vu.edu.au
}

\begin{abstract}
This paper reports on the impact and benefits of integrated business learning (IBL) on student learning in vocational Information Communication Technology (ICT) courses. Student reactions to learning experiences located in workplaces and those that model work-practices are explored through experiential learning theories and employability models. Using surveys, in-depth interviews and focus groups, the student voice is captured and triangulated with teacher and industry practitioner observations of student capabilities and employability. The findings show that students highly value and benefit from IBL that provides meaningful connections to the real world of work. Learners are motivated by structured and tailored experiences that provide a strong alignment between the curriculum and professional practice, providing opportunities for both personal and professional development. The critical importance of authentic and situated learning postulated by social development theories is validated in these evaluation findings, which also highlight the efficacy of government facilitated industry engagement for inducing curriculum innovation.
\end{abstract}

Keywords: Integrated Business Learning, ICT Education, Experiential Learning 


\section{INTRODUCTION}

Integrated business learning (IBL) describes a variety of approaches that integrate study and work. Terms such as experiential learning, work-integrated learning, professional learning and practice-based learning are commonly used to describe a range of authentic and situated learning experiences observed in post-compulsory education. IBL is increasingly used to respond to student and employer demands to improve employability and work-readiness. This paper seeks to evaluate the impact and benefits of these approaches.

This paper presents an evidence-based approach that evaluates the effectiveness of the ICT Skills - TAFE IBL Program (IBL Program) funded by the Victorian Government Department of Business and Innovation $(\mathrm{DBI})^{1}$, targeting students enrolled in ICT courses in Technical and Further Education (TAFE) institutions. Seed funding is provided to help establish or further enhance IBL programs and develop new industry partnerships to expand opportunities for student experiential learning. The IBL Program responds to declining enrolments in ICT courses and projected ICT skills shortages in Australia $\left(\mathrm{DBI}^{2}\right.$, Australian Computer Society ${ }^{3}$ ). The IBL Program guidelines identify several objectives: increase the number and quality of IBL placements; raise students' awareness of potential ICT career pathways and transitions; provide new career, employment and training outcomes; and develop and demonstrate employability skills of ICT students. This research paper presents an evidence-based evaluation of program outcomes and benefits for key stakeholders.

\section{EVALUATION METHODOLOGY}

A multi-method approach was developed for the evaluation which included a post-program online survey of students (42 responses); semi-structured interviews with 8 students, 6 teachers and 4 industry supervisors; and 2 student focus groups. The survey and interview questions where designed after the development of a detailed evaluation framework that aligned intended outcomes to program activities and outputs. This enabled us to collect data and information that directly related to the purported benefits and impact of IBL identified by the funding body and educational institutions. Survey and interview question design was also informed by a detailed review of the literature related to experiential theory, detailed briefly in the following section. 9 TAFE departments from 8 institutions participated in the evaluation. The size of each IBL program differed across participants and ranged from less than 20 to over 60 students. The length of placements also varied, with several programs running for 
12-15 weeks. A variety of IBL models or approaches were identified: industry placements (paid/unpaid), business simulation (e.g. operating a practice firm), industry-based projects for external business clients, industry speakers, presentations to industry, networking and industry mentoring.

\section{LITERATURE REVIEW: LINKING EXPERIENTIAL LEARNING THEORIES TO THE EVALUATION APPROACH}

Experiential and work-integrated learning theories draw on an array of educational and development theories. Social Development Theory posits that cognitive development takes place in a social context where learners interact with "more knowledgeable others", a concept central to IBL. Constructivism is based on acquisition of knowledge and understanding being developed through active rather than passive learning. The context for learning is particularly important if learners are to have realistic and meaningful experiences. In the Situated Learning paradigm ${ }^{5}$, workplaces are authentic contexts for learning about work and future careers. Near or quasi-authentic contexts (for example, simulations and industry-based projects) can oftentimes be as effective as being physically located in a workplace.

This evaluation is informed by Kolb's ${ }^{6}$ Experiential Learning Theory, which depicts the learning cycle with four stages: concrete experience (feeling); reflective abstraction (watching); abstract conceptualization (thinking); and active experimentation (doing). While valuable at a general level, Knight and Yorke ${ }^{7}$ believe that Kolb's approach obscures personal qualities and attributes, and warn against "tokenistic thinking (where) employability is reduced to key skills" (p. 263). Employability is the outcome of a complex learning process, in which generic skills are but one element that "needs to be continually refreshed throughout a person's working life", "Situatedness", the ability of students to navigate and negotiate the social, political and practical dimensions of a workplace. is also central to the conception of employability.

\section{EVALUATION FINDINGS}

This section presents the evaluation findings on the benefits of the IBL program and its impact on learners. It draws principally on student experiences and perceptions of the impact on learning (including career development learning) via the application of skills and knowledge in a situation a student has encountered or would expect to encounter in a 
workplace. Overall, the findings support the value of IBL for the development of graduate capabilities, employability and for career transition and pathways. These outcomes are validated in interviews with teachers and industry partners.

\subsection{Student Learning}

A strong theme through the interviews was that program activities whether they were projects or placements - were designed to provide opportunities for students to apply what they have learned in a real life context; practice and extend technical and employability skills; develop confidence, professional presentation and technical competence; and come away with experience that will help them gain employment.

Typically, program managers wanted students to "get practical experience" and to see if their skills match with industry standard. Others said they wanted students to get "hands on experience putting theory into practice" and that it was "training for the real world for both technical and soft skills" because students have limited knowledge about the world of work. Helping students gain employment upon program completion was also strong motivator. As one Program Manager noted, these types of activities help to "give students the experience that all job ads say they need."

This vocational orientation and IBL's role is strongly emphasized and very relevant to the students. According to one program manager "learning key employability skills is a major opportunity for new skill acquisition in the program. The activities and experience help with the hidden curriculum, which some students fail at and need to be supported to work through". The IBL Program had provided a vehicle through which to do this effectively. The program gave some students opportunities to develop their language, literacy and numeracy through the work placement. Students' confidence also increased, "particularly with now having experience which they can use when looking for work. (It) has exposed them to working in a professional environment, makes them realize their course is right for them and they do want to pursue a career in this area. They also benefit from hearing from industry that there are jobs and careers for them out there".

These outcomes were also recognized by students as being valuable for their personal and professional development. For example, students who were interviewed said that their placement supervisors had discussed further study and career pathways, and said that it was "very motivating to see role models in the profession that they can aspire to." Students also reported that 
they had mostly been able to realize the outcomes that teachers hoped for them from the placement or project experience.

The industry partner's critical role has been noted by educators who stress the importance of client selection for successful projects and who caution that selecting the right partner can be critical to creating a meaningful learning experience for students. There was also awareness amongst TAFE staff as to differences in the motivations for industry to be involved in the program that impacted on the quality of the learning outcome for the student. Among the reasons cited for participation by industry partners were altruism, expressing a desire to help the students and the TAFE, a desire to obtain an outcome they might not otherwise be able to afford (such as having students complete a project or other work that otherwise might not have been undertaken), looking for potential employees and opportunities to communicate to educational providers what they as employers need.

The student survey of program impact revealed a significant perceived impact on a broad range of capabilities and employability. Around three-quarters of students agreed that the program improved their work-related knowledge and skills (79\%), and that it contributed to the development of their critical thinking skills (74\%). A similar number (71\%) agreed that the program improved their written communication skills, with over half (55\%) agreeing that it helped develop their written communication skills. The vast majority of students agreed that their ability to work effectively with others improved (88\%) as did their ability to work independently $(80 \%)$. Over $70 \%$ of students agree that IBL enhanced their problem solving skills and ability to analyze complex problems.

\subsection{Career Transition and Pathways}

At interview, students demonstrated considerable insight into their level of technical and professional competence and into possibilities for future employment or further education. They commented about being able to put their professional and technical skills together to produce a product that they could then use as "proof" of what they can do for a prospective employer. They were also aware of the different skill sets that different roles require, and appeared quite knowledgeable about where they can look for employment, who they would be employed by and what role they were suited to. This understanding came about mainly through their coursework, but the students interviewed also felt they had benefited in terms of understanding career structures and pathways by being exposed to industry models through placement and projects. 
Strong alignment of program activities with the curriculum was evident across the programs. Students were able to link and contextualize coursework knowledge and skills to their application in the workplace. While one particular student did not find this work technically difficult, workplace team dynamics and the demands of competing tasks was critical to learning. "Skills in project management particularly the team dynamics side were important... some of these skills (were) developed through the course but I was able to broaden these skills. (It was a) Good experience and interesting to see in the real world how to manage competing demands which was by far the most challenging and possibly where I learned the most." The IBL experiences these students were exposed to appear to reinforce messages they receive through their coursework, which are strengthened by concrete examples.

This is supported by student responses to the online survey and provides further evidence of improved knowledge of transitions and pathways to employment because of the IBL Program. The majority of students believe that the IBL Program provided them a better understanding of the skills and attributes required for work in an ICT related field (74\%) and that they can now better connect coursework learning to the knowledge and skills needed in an ICT job, and have further developed their employability skills (77\%). Connected to this realization, students indicated that the program had allowed them to reflect on their course and its relationship to the "real world" and future job opportunities, and as a result most students (73\%) now feel more confident because they have the skills to be employed in an ICT-related job. Clearly, experiential learning, in a variety of forms, improves student confidence and employability. IBL activities often lead to employment opportunities for students with the businesses involved in the program. Of the 15 survey respondents who indicated their IBL Program involved working or doing a project for a real business, this has led to current or prospective employment for 8 of them.

\subsection{Demonstrated Value of IBL Experiences}

There are two main ways to demonstrate the value of these experiences: through stakeholder perceptions of the experience and through resultant the artifacts or outcomes. All students, staff and industry partners say that placements and projects are an excellent opportunity for students to apply their skills in a real world context, which helps prepare them for later employment. TAFE staff believed that students better understand the career options and educational opportunities open to them. There seems to be good anecdotal evidence that the programs have achieved the desired learning outcomes. Students who were interviewed reported that IBL had provided them with practical experience that they couldn't get easily (or at all) in the 
classroom, that they felt more confident about their technical and professional skills, that they needed to draw together everything they had learned to complete the project or placement and that they had consolidated or extended their technical skills.

Industry partner feedback supports the students' perceptions of positive learning outcomes. TAFE staff firmly believed that students are able to achieve the desired learning outcomes, citing as evidence: successful completion of projects to client's satisfaction; repeat engagements with industry on projects or placements; the observable changes in students across the course of the project or placement; and offers of employment to students as a result of project work or placements.

The principal learning outcome is to provide students with experience of work, which these programs do offer. Achievement of the learning outcome relating to opportunities to practice and extend technical and employability skills is not explicitly measured but is designed into the experience when the project or placement is set up. Both the students and staff report that the experience helps participants develop confidence, professionalism and technical competence. The program's achievement of desired outcomes is shown by the fact that a number of students have been offered employment as a result of placements or project work.

Results from the survey reveal that most students (73\%) agree that their IBL experience had improved their confidence in being work-ready, with a similar proportion indicating they have a better understanding of what it would be like to work in an ICT related field. Nearly three-quarters of respondents $(72 \%)$ indicate that they were more likely to pursue a career in ICT, supporting evidence in the interviews that practical and relevant experiential learning develops confidence and supports transitions into related careers. Around two-thirds now feel more engaged and motivated about their studies as a result of their IBL experience (63\%), and believe they have greater knowledge of future employment options (67\%).

Overall, acknowledging the challenges associated with placements or projects for students, all involved in these programs perceived them as positive and valuable. Staff did describe situations where students "failed" work placement and were "sent back" by industry partners. This created work for staff to mend fences, which for some industry partners was not possible. But for the most part, the experiences were constructive and any problems could be ironed out. Students involved in projects at one institution described feeling challenged and stressed at times, but also described "satisfaction with working hard and creating a final product". The positive feedback and constructive criticism from their peers and the support 
of teachers helped them to overcome these challenges and complete the project successfully and on time.

Industry partners who were interviewed were positive about the benefits, with one noting that it was a challenge for students to move from a structured program of lectures and tutorials to one where they need to be independent and organize their own work. This particular partner felt that the students did good work, but that given more resources they could have done even better. He saw the program as being a means of helping to transition students successfully from school to work. TAFE staff also emphasized that the outcomes of the student projects or placements were evidence of the success of the program. They also pointed to the fact that most of their industry partners had students for more than one placement, were involved in more than one project, or recommended the program to others in their network. Finally, almost all TAFE staff had students who had been offered employment as a result of their involvement in the program.

\section{CONCLUSIONS}

It is obvious that staff and students see the benefits of this program, and that industry sees that there can be benefits for themselves, students and TAFE. The "learning by doing" that the program provides, through placement and projects, and the exposure to industry models through other experiential learning activities, appears to be an important element that had been missing for these students. Staff involved with the program were keen to overcome challenges and, if possible, expand and enhance TAFE in the future. What is clear is that the government seed funding provided the stimulus to develop IBL curriculum and establish new industry partnerships and learning opportunities for students.

This research required the development of a set of evaluation tools that could be applied to other IBL learning programs embedding in post-secondary education curriculum and customized for discipline or institutional specific approaches. This could include the inclusion of a range of attributes and attitudes that underpin self-efficacy, employability and career development. Evaluations of this nature are important for confirming that programs achieve their desired goals and are worthy of funding. More importantly, different models for implementing WIL and good practice guidelines can be identified which will assist the many other educators and industry partners involved in IBL initiatives. 


\section{REFERENCES}

[1] Department of Business and Innovation, Victorian ICT Action Plan. Retrieved on February 1, 2011, from http://ict-industry-reports.com/wp-content/uploads/sites/4/2010/10/201 0-VIC-ICT-Action-Plan-Oct-2010.pdf.

[2] Department of Business and Innovation, 2009 ICT Skills Snapshot: The State of ICT Skills in Victoria. Retrieved on February 1, 2011, from http://www.business.vic.gov.au/_data/assets/pdf_file/0018/52047/prtlict-ICT-Skills-Initiatives.pdf.

[3] Australian Computer Society, Review of the Skilled Occupations List. Retrieved on February 1, 2011, from http://www.acs.org.au/index.cfm?action=show\&conID=201012060951 344582.

[4] L.S. Vytgotsky, Mind and society: The development of higher mental processes. Cambridge, MA: Harvard University Press, 1978.

[5] J. Lave, Cognition in practice: Minds, mathematics and culture in everyday life. Cambridge, New York: Cambridge University Press, 1998. http://dx.doi.org/10.1017/CBO9780511609268.

[6] D.A. Kolb, Experiential learning: Experience as the source of learning and development. New Jersey: Prentice Hall, 1984.

[7] P.T. Knight, and M. Yorke, Employability through the curriculum. Tertiary Education and Management 8(4), p261-276, 2002. http://dx.doi.org/10.1080/13583883.2002.9967084.

[8] M. Yorke, Employability in higher education: What it is - What it is not. Retrieved on February 1, 2011, from http://www.heacademy.ac.uk/assets/documents/tla/employability/id116 _employability_in_higher_education_336.pdf. 
